\title{
Individual Rank and Response: Survey-Based Evidence on the Effects of Rank-Based Performance Feedback
}

\author{
Martin Huschens \\ Claus-Peter H. Ernst \\ Franz Rothlauf \\ Johannes Gutenberg-Universität Mainz CBS International Business School Johannes Gutenberg-Universität Mainz \\ huschens@uni-mainz.de \\ c.ernst@cbs.de \\ rothlauf@uni-mainz.de
}

\begin{abstract}
Evidence suggests that rank-based performance feedback (RBPF) can influence workplace performance. Still, knowledge about the differential effects of RBPF on two central antecedents of employees' performance - perceived pressure and individual goal-setting - is still sparse. We address these gaps by using a survey-based study and found that the effects of RBPF on individual goal-setting are positive for high, intermediate, and low performing individuals. However, these positive effects come with a price: Low performers who find themselves at the bottom of the ranking perceive their situation as more pressuring compared to a situation without ranking. Although these results point to a potential benefit, they also cast doubt on the implementation of rankings within the workplace.
\end{abstract}

\section{Introduction}

Companies are interested in increasing the workplace performance of their employees. Receiving feedback is commonly accepted as an important driver of employees' workplace performance [1, 2, 3, 4]. As a result, different kinds of IS-enabled feedback regimes have been implemented in a number of organizations. Due to the recent trend towards implementing gamification techniques such as leaderboards into the workplace, rank-based performance feedback (RBPF) regimes — which provide social standards against which individual performance is gauged - have now become especially popular $[5,6]$.

Recent evidence suggests that RBPF can positively influence workplace performance [1, 7, 8, 9]. More specifically, one channel having performance enhancing effects is that RBPF can lead to an increase in individuals' goal-setting by (1) allowing to identify with successful targets, and (2) reducing uncertainty about the true status of one's ability and possibly attainable performance levels [10, 11, 12, 13, 14, 15]. However, research also suggests that the introduction of RBPF into the workplace may have detrimental effects on workplace performance: Feedback regimes can create an excessively competitive and pressuring workplace due to employees' constant strive for better ranks (e.g., $[16,17])$.

Still, one central aspect of RBPF has not yet been the focus of intense research in workplace settings. More specifically, the influence of individuals' ranking positions on perceived pressure has been largely neglected, although there are good arguments for the pressuring effect of RBPF potentially varying a great deal across the performance distribution of a ranking: Indeed, studies have shown that in upward comparisons (i.e., comparisons to others that are betteroff), which are typical in the case of low performers, individuals are made aware of their lack of skill, status, or position, which increases their perceived stress [16]. In contrast, downward comparisons (i.e., comparisons to others that are worse-off), which are typical in the case of high performers, are capable of reducing stress states $[18,19]$. As a result, we expect that introducing RBPF into the workplace (a) increases perceived pressure for low and intermediate performing individuals, and (b) decreases perceived pressure for high performing individuals.

Similarly, no study that we know of has examined how people respond to their ranking position in terms of their individual goal-setting. As a result, we also analyze RBPF's influence on (c) individual goalsetting across the performance distribution of a ranking.

In order to evaluate the influence of RBPF on perceived pressure and individual goal-setting across the performance distribution, we conducted a factorial survey with 416 respondents and a repeated-measures between-subjects design with three treatment groups: low performers (Group 1), intermediate performers (Group 2), and high performers (Group 3). The baseline condition provided our subjects with a criterion-based performance feedback (CBPF) that allowed them to compare their performance to a predefined performance level. Following this, subjects had to answer a questionnaire on perceived pressure 
and had to set an individual goal for their future performance. Respondents then received a vignette that provided RBPF, which allowed for social comparison by placing the low performers at the bottom rank, intermediate performers at the middle rank, and high performers at the top rank. Finally, subjects had to once again answer the questionnaire and indicate a performance goal.

\section{Rank-based performance feedback}

Providing feedback is essential to foster workplace performance and guide employees' efforts to meeting an organization's objectives. Feedback is defined as "information about the gap between the actual level and the reference level of a system parameter which is used to alter the gap in some way" [20, p. 4].

In many cases, providing feedback entails presenting information to employees about their progress towards attaining predefined goals - thus allowing them to compare their actual performance to a given reference level [21]. In educational psychology, this type of feedback is also referred to as criterionbased assessment or feedback (CBPF) in which an individual's absolute performance is evaluated against a predefined scale [22, 23]. Usually, this type of feedback regime relies on feedback being given privately. As a result, comparisons to an absolute level allow for competition, but only with one's self [24].

Another frequently-used type of feedback is relative performance feedback, which allows for the interpersonal comparison of one's progress, abilities, or work outcomes to social reference levels [21]. More specifically, an individual's performance is assessed in relation to other individuals based on their relative performance $[22,23]$. In particular, relative performance feedback often relies on publiclyannounced performance rankings (e.g., inside a company's intranet). This so-called rank-based performance feedback (RBPF) allows for social comparison and, as a result, also allows employees to compete with each other.

Studies have shown that RBPF can influence workplace performance through some of its main antecedents. More specifically, RBPF reveals people's social ranking, which can influence an individuals' goal-setting. This, in turn, can drive workplace performance $[3,12,21,25]$. At the same time, $\mathrm{RBPF}$ can also be demoralizing and create an excessively competitive and pressurizing workplace, which can negatively affect workplace performance [16]. In summary, RBPF is commonly accepted as an important (indirect) driver of workplace performance through individual goal-setting and perceived pressure. However, we believe that the effects generated by
RBPF may well vary for subjects at different positions within a performance distribution. In other words, we believe that the introduction of RBPF has a different impact on the main antecedents of workplace performance, depending on the individual's rank. Thus, in the following sections, we will build hypotheses regarding the influence of $\mathrm{RBPF}$ on perceived pressure and individual goal-setting according to an individual's position in the performance distribution.

\section{Research model}

\subsection{Perceived pressure}

Perceived pressure is commonly defined as the perceived presence of situational incentives for optimal, maximal, or superior performance [26]. It is different from the active pressure-exerting behavior of peers, colleagues or supervisors. Indeed, perceived pressure is rather an inherent passive feeling that people experience as a reaction to specific situations, such as working in a competitive environment.

According to the theory of social comparison processes [27], people have an inherent desire to compare themselves to others in order to relate their own features (abilities and opinions) to those of relevant peers. Moreover, they deeply care about their relative performance ranks. It is widely acknowledged that social comparisons lead to competition, as comparing to others either makes individuals aware of their lack of skill, status or position, or of their success [16]. Competition can be defined as situations in which individuals' outcomes are opposed and the gain of one comes at the loss of the other [28]. This means that individuals' goal attainments are negatively correlated with each other: A better performance and, hence, a higher social status for one subject is always linked to a lower performance and, hence, a lower social status for other subjects [29]. As a result, competitions can be perceived as pressuring, as users might feel they need to constantly perform better than others.

Studies have shown that the urge to perform better and better can have detrimental effects on performance. This is commonly referred to as choking under pressure [26] and describes performance decrements in situations in which good or improved performance is especially important. Moreover, pressure can also be counterproductive when cooperation is important - for instance, if it encourages workers to behave unfairly and to sabotage each other $[30,31,32]$. As a result, it is important for employers to know the antecedents of perceived pressure so that they can, if necessary, prevent it from emerging. 
RBPF allows individuals to compare themselves to others since the information on social entities (including oneself) is set in relation to others. Introducing RBPF into the workplace can thus be expected to influence employees' perceived pressure levels due to their constant striving for better ranks. Research on perceived pressure as an outcome of RBPF is sparse. [33] found no significant evidence that rankings lead to increased feelings of situational pressure while [17] found pressuring effects in gamified working situations based on intensified social comparison processes. However, both studies do not investigate individual ranking positions. We believe that the pressuring effect of RBPF may vary across the performance distribution.

More specifically, RBPF offers opportunities for both downward comparisons and upward comparisons, depending on individuals' position within the ranking. Whereas upward comparison refers to individuals' comparison to better-off individuals, downward comparison describes individuals' comparison to worse-off individuals [34]. In the literature on social comparison, studies have shown that downward comparisons, which are typical for high performers, can reduce stress states [18, 19]. In contrast, when individuals make upward comparisons, which is typical for low performers, they are made aware of their lack of skill, status, or position, which increases their perceived stress. In particular, if subjects perceive their upward targets to be threatening [35], upward comparisons are perceived to be ego-deflating and stressful. In line with this, [29] and [16] showed that low performers are put under intense pressure to exhibit competitive behaviors.

Based on these theoretical insights regarding social comparison processes, we hypothesize that the effects of introducing RBPF into the workplace might well differ for subjects in different positions within the performance distribution. More specifically, we postulate that the introduction of RBPF decreases the perceived pressure of high performing individuals at the top of the ranking and increases the perceived pressure of low and intermediate performing individuals at the bottom and in the middle of ranking, respectively. Indeed, only high performers are in a position that solely allows for downward comparisons. In contrast, both the low and intermediate performers are placed in a situation where they are made aware of their shortfalls, and are, thus, put under intense pressure. We hypothesize that:

\section{Introducing rank-based performance feedback into the workplace}

(H1a) increases perceived pressure for low performing individuals.
(H1b) increases perceived pressure for intermediate performing individuals.

(H1c) decreases perceived pressure for high performing individuals.

\subsection{Individual goal-setting}

Individuals draw inferences about their capabilities via social comparisons, especially when they are uncertain about their abilities [36]. Since RBPF provides social comparison information, it is a useful source to form individual goals and to consequently adjust performance levels. In addition, research indicates that individuals may not only respond to such comparisons by attempting to adjust performance to match their goals - indeed, they may also revise their goals in light of their performance [37], providing a further avenue through which individual goal-setting can increase performance. As such, individual goals are not static entities — rather, individuals frequently revise their personal performance standards up and down often as a reaction to being confronted with feedback.

Empirical research has found individual goalsetting to have positive effects on self-regulatory processes and outcomes such as effort, and persistence, which in turn drive workplace performance (e.g., [37, $38,39]$. As a result, it is especially important for employers to understand how individual goal-setting is shaped by feedback interventions in order to support workplace performance in the end.

On the whole, goals play an important role in RBPF. Indeed, an inherent feature of the RBPF is that it makes performance more salient, subsequently allowing individuals to form individual performance goals. This means of creating goals through RBPF deviates from traditional workplace situations. Indeed, whereas in traditional workplaces the individual goals of the workers are created by the supervisors, in ranking situations, the goals are created by the workers themselves [40].

Uncertainty concerning the relative status of one's performance is an essential component that impedes the upward goal revision and subsequent effort enhancements. Since RBPF reduces individuals' uncertainty about their status and leverages social information about their capabilities, we believe that RPBF can lead to upward goal revisions. We believe this to be especially true in the case of downward comparisons: In these cases, subjects experience the success of outperforming others, thus increasing their perceived individual goal-setting. As a result, they may raise their self-set performance goals and thus positively influence their performance [37]. However, we suspect that this positive effect should hold true 
across the entire performance distribution, and not just for high and intermediate performers. This means that low performing individuals could also experience these positive effects, as long as reaching a social standard (that is, a higher rank) is perceived as attainable [38, 39]. The ranking could also provide important information to the low-performing individuals: First, observing others who are proficient at a task can reveal useful information about how to improve oneself [41]. Second, individuals may come to identify themselves with successful targets and perceive them as role models, and leading to the imitation of the target's actions [42]. Third, seeing others succeed may propel people to set higher personal standards, which can motivate efforts towards these new and higher goals [15]. We hypothesize that:

Introducing rank-based performance feedback into the workplace increases individual goal-setting for

(H2a) low performing individuals.

(H2b) intermediate performing individuals.

(H2c) high performing individuals.

\section{Research design}

\subsection{Factorial survey}

To test our hypotheses, we conducted a factorial survey (also called vignette study) [43]. Vignettes are "short, carefully constructed description[s] of a person, object, or situation, representing a systematic combination of [the investigation-relevant] characteristics" [44, p. 128]. Respondents are then confronted with these different fictional situation descriptions and asked to assess them on the basis of a questionnaire. The situation descriptions may consist of a situational textual description, a video, illustrations, or any other form of stimulation.

In our context, we asked our respondents to imagine that they were a call center agent:

"Please imagine the following situation: Your name is B. Smith and you are working as an agent in a call center. Your job is to gather data for market research in the food industry. You are working in an open space office with 29 other call center agents. This is what you see on your intranet:"

We then differentiated between three conditions by giving a different performance level (high, intermediate, low) to each group. More specifically, the criterion-based performance feedback (CBPF) provided to each group was either below the reference level (low performers), at the reference level (intermediate performers), or above the reference level (high performers). Overall, we defined a performance of $160 / 200 / 240$ calls as being below the reference level/at the reference level/above the reference level, which corresponds to respectively $40 / 50 / 60$ percent of the 400 target calls. All respondents were randomly assigned to one of the three performance groups. Following the introductory text, the vignettes further explained:

"The performance goal of 400 calls per agent has not been met for several months. Hence, you and your colleagues were asked to put more effort into reaching this goal. Your payment does not depend on your individual performance. ${ }^{\text {. }}$,

The subsequent questionnaire included items that measured participants' perceived pressure. These items were taken from a well-tested measurement instrument: the Intrinsic Motivation Inventory's pressure/tension subscale [45]. The three items were measured using a seven-point Likert-type scale ranging from "strongly disagree" to "strongly agree". Furthermore, we asked the respondents to set a goal with regards to the number of calls they trusted themselves to reach that month:

"Based on the performance feedback you saw, please fill in the number of calls you trust yourself to reach in total by the end of the month. There is no right or wrong answer. Fill in the number of calls which is realistic for you.".

This allowed us to infer individual goal-setting which was operationalized as the difference between the individuals' self-set performance targets and the externally predefined goal of 200 calls after half a month $^{2}$.

To make sure that the priming was successful, subjects had to recall the vignette situation after answering a few of the questions in the questionnaire. For example, we asked them what their name and job was in the vignette. If the subjects were unable to answer these questions correctly, we repeated the priming by presenting the vignette once again.

Furthermore, we gathered data on subjects' social comparison orientation and performance orientations because research has shown that these covariates are important determinants of people's reactions to

\footnotetext{
${ }^{1}$ We excluded any monetary aspect of tournaments and rankings in order to (1) make a distinction to a related strand of research in the field of economics that deals with the design of optimal labor contracts and tournament incentive [52], and (2) to focus on the consequences of social comparison processes and the pursuit of social status in the absence of monetary incentives. This allowed us to capture the non-pecuniary motivational and pressuring effects of rank-based performance feedback.

2 This individual goal-setting measure is highly related to the vignette situation since participants have to incorporate the ability of the vignette character in order to provide a realistic goal. Hence, we assumed that this particular operationalization would provide a more accurate measure for individual goal-setting than questionnaire items would provide in our vignette study.
} 
rankings [36, 46, 47]: People indeed differ in their tendencies to engage in social comparisons, and social comparison orientation is a trait that reflects these individual differences [47]. Individuals who show a high level of social comparison orientation have a sensitivity to and awareness of others. Thus, for those individuals, the effects of providing social comparison information, such as through RBPF, are likely to be intensified. Furthermore, individuals may have (a) a desire for success because they perceive achievement settings such as games and competitions to be challenging (called performance orientation-approach); or they may have (b) a desire to avoid failure because they perceive competitions as being potentially threatening (called performance orientation-avoidance) [46]. Hence, the effects of RPBF can also be influenced by the individuals' performance orientations. Table 1 presents our measurements.

Table 1. Measures, items' loadings (t-values)

\begin{tabular}{|c|c|c|c|c|c|}
\hline & & PP & AP & AV & SC \\
\hline PP1 & $\begin{array}{l}\text { The performance target makes me feel } \\
\text { nervous. }\end{array}$ & $\begin{array}{l}.845 \\
(27.1)\end{array}$ & -.103 & .193 & .052 \\
\hline PP2 & $\begin{array}{l}\text { I feel put under pressure by the } \\
\text { performance feedback. }\end{array}$ & $\begin{array}{l}.815 \\
(17.7) \\
\end{array}$ & -.026 & .110 & .039 \\
\hline PP3 & $\begin{array}{l}\text { I find working toward my goals to be } \\
\text { very stressful. }\end{array}$ & $\begin{array}{l}.905 \\
(44.2)\end{array}$ & -.107 & .272 & .071 \\
\hline AP1 & $\begin{array}{l}\text { In games and competitions, I always } \\
\text { strive to win. }\end{array}$ & -.118 & $\begin{array}{l}.915 \\
(70.8)\end{array}$ & -.350 & .410 \\
\hline AP2 & $\begin{array}{l}\text { I always want to be the first in games } \\
\text { and competitions. }\end{array}$ & -.080 & $\begin{array}{l}.941 \\
(162.6)\end{array}$ & -.352 & .538 \\
\hline AV1 & $\begin{array}{l}\text { In games and competitions, I only try to } \\
\text { avoid doing poorly. }\end{array}$ & .252 & -.128 & $\begin{array}{l}.681 \\
(8.7)\end{array}$ & .098 \\
\hline AV2 & $\begin{array}{l}\text { In games and competitions, I am } \\
\text { satisfied with a place in the midfield. }\end{array}$ & .194 & -.415 & $\begin{array}{l}.940 \\
(35.6)\end{array}$ & -.148 \\
\hline $\begin{array}{l}\mathrm{SCO} \\
1\end{array}$ & $\begin{array}{l}\text { For me, success means to be better than } \\
\text { others. }\end{array}$ & .054 & .525 & -.117 & $\begin{array}{l}.942 \\
(128.7)\end{array}$ \\
\hline $\begin{array}{l}\mathrm{SCO} \\
2\end{array}$ & $\begin{array}{l}\text { I am very much looking at how well I } \\
\text { perform in comparison to my colleagues. }\end{array}$ & .072 & .415 & -.022 & $\begin{array}{l}.901 \\
(54.1)\end{array}$ \\
\hline
\end{tabular}

After answering the questionnaire, we introduced a RBPF into the vignette situation by means of a leaderboard. Whereas our respondents up until then only had information about their individual performance, they now also had knowledge about their peers, enabling them to compare themselves with others through this relative performance feedback. The continued vignette description read as follows:

"After half a month has passed, the average number of calls did not change by much. For this reason, your boss wants to give you better feedback to reach the desired calls for the month. To reach the performance goal more frequently, the performance feedback feature in your intranet was updated. In addition to individual performance feedback, there is also a ranking list to give you and your colleagues comparison feedback. The feedback refers to your performance after 15 days of the current month, so you still have 15 days to reach your goal of 400 calls. Your payment still does not depend on your individual performance and/or ranking position."

Following this, the leaderboard was presented to the respondents. Respondents that previously performed below the reference level, met the reference level, or performed above the reference level were shown a ranking of $1 / 15 / 30$ respectively (i.e., the first/middle/last position on the leaderboard ${ }^{3}$ ).

In the final step, all participants had to yet again answer the questionnaire described above, in addition to a few demographic questions.

In summary, our vignette study consisted of three groups that were first given criterion-based performance feedback (CBPF) with no information about their peers (t0). Their position in the performance distribution was either below the reference level, at the reference level, or above the criterion-based reference level (Groups 1, 2, and 3). Each respondent then had to answer items for our perceived pressure measure and, in addition, had to indicate a personal goal to measure their individual goal-setting. Following this, the respondents again received performance feedback, though this time, in $\mathrm{t} 1$, it was relative performance feedback provided by a ranking (RBPF). Finally, the respondents yet again answered the questionnaire. Overall, this research design enabled us to: (1) evaluate the influences of performance transparency on each of our dependent variables (within-subject) through the use of a ranking; and (2) analyze whether these effects differed for different positions in the performance distribution (low, intermediate, high; between-subject).

\subsection{Data collection}

In January 2018, we recruited English-speaking respondents via Amazon Mechanical Turk over a period of two weeks. More specifically, speaking English was an obligatory qualification for participation in the study, and we promised a reward of 1 \$ per questionnaire. In this manner, we obtained 732 online questionnaires. However, we had to drop several datasets from our sample: First, we dropped 216 datasets where the respondents repeatedly answered our priming-control questions incorrectly.

\footnotetext{
3 The performance level itself did not change per respondent. For example, respondents that performed below the reference level / had met the reference level / performed above the reference level in the criterion-based performance feedback (CBPF), also received a bottom / middle / top rank in the rank-based performance feedback (RBPF). Thus, the RBPF confirmed the CBPF, respectively.
} 
Furthermore, we dropped 39 datasets that were answered very quickly by the respondents (less than 6 minutes, which was equal to the average time to complete the questionnaire minus the standard deviation). Finally, we dropped certain datasets due to an obvious/invalid answer scheme (identified through reversed questions and the open question on the personal goal).

As a result, we had a final sample size of 416 respondents. Our sample consisted of 50.7\% male respondents with a mean age of $36.6(\mathrm{SD}=12.28)$. Nearly $60 \%$ of our respondents indicated that they were currently employed. According to the results of the Kruskal-Wallis tests, one-way Analyses of Variance (ANOVA) and Pearson's Chi-Square tests, no significant difference was detected across treatments in gender, age, current profession, social comparison orientations, or performance orientations. This suggests a successful random assignment of subjects to our treatment groups and supports the claim that the treatment groups did not differ with regards to these important covariates. This means we could rule out structural group differences as being the cause of any differences found in our dependent variables between groups. ${ }^{4}$

\section{Results}

\subsection{Measurement model}

To evaluate our measurement model, we performed a confirmatory factor analysis in t0 for our Likert-type scales via SmartPLS 3.2.4 $[48]^{5}$. To test for significance, we used the integrated bootstrap routine with 5,000 samples [49].

Tables 2 and 1 present the correlation between constructs together with the Average-VarianceExtracted (AVE) and Composite-Reliability (CR), and our items' factor loadings, respectively: AVE and CR were at least .674 and .801, respectively, meeting the suggested construct reliability thresholds of .50 and .70 [50]. All items but one (AV1: $\lambda=.681, \mathrm{p}<.001)$ loaded high (at least .815) and significant $(\mathrm{p}<.001)$ on their parent factor and, hence, met the suggested threshold of indicator reliability of .70 [50]. Nevertheless, we kept AV1 in our measurement model: "[I]ndicators with loadings between 0.40 and 0.70 should only be

\footnotetext{
4 The demographics of our final sample as well as the results of the randomization check are available on request from the authors.

${ }^{5}$ Another confirmatory factor analysis was performed in $\mathrm{t} 1$ and came to the same conclusions regarding construct reliability, indicator reliability, and discriminant validity as the one performed in t 0 . The detailed results can be requested from the authors.
}

considered for removal from the scale if deleting this indicator leads to an increase in composite reliability above the suggested threshold value" [49, p. 145] which was not the case in our analysis since all CRs already met their suggested threshold as indicated above. We thus kept all the indicators initially used. Finally, the loadings from our indicators were highest for each parent factor and the square roots of the AVE of all constructs were larger than the absolute value of the constructs' correlation with each other, thus indicating discriminant validity.

Table 2. Correlation between constructs, AVE, CR

\begin{tabular}{|c|c|c|c|c|}
\hline & PP & AP & AV & SCO \\
\hline Perceived Pressure (PP) & $\begin{array}{l}.733 \\
(.891) \\
\end{array}$ & & & \\
\hline $\begin{array}{l}\text { Performance Orientation- } \\
\text { Approach (AP) }\end{array}$ & -.105 & $\begin{array}{l}.861 \\
(.925)\end{array}$ & & \\
\hline $\begin{array}{l}\text { Performance Orientation- } \\
\text { Avoidance (AV) }\end{array}$ & .248 & -.378 & $\begin{array}{l}.674 \\
(.801)\end{array}$ & \\
\hline $\begin{array}{l}\text { Social Comparison } \\
\text { Orientation (SCO) }\end{array}$ & .067 & .516 & -.082 & $\begin{array}{l}.850 \\
(.919)\end{array}$ \\
\hline
\end{tabular}

Note: Diagonal elements are the AVEs with the CRs in parentheses; offdiagonal elements are the inter-construct correlations.

\subsection{Hypotheses testing}

Our focus lies on identifying the effects of RBPF for individuals in different positions of the performance distribution. Table 3 presents the means and standard deviations of our outcomes as a function of the feedback regime (No RBPF vs. RBPF) and the individual's performance group (low, intermediate, high).

\section{Table 3. Descriptives}

\begin{tabular}{|c|c|c|c|c|c|c|c|}
\hline & & \multicolumn{3}{|c|}{$\begin{array}{l}\text { No Rank-Based } \\
\text { Performance Feedback, t = } \\
\text { 0 (NoRBPF) } \\
\text { Mean (St. Dev.) }\end{array}$} & \multicolumn{3}{|c|}{$\begin{array}{l}\text { Rank-Based Performance } \\
\text { Feedback, t = } 1 \text { (RBPF) } \\
\text { Mean (St. Dev.) }\end{array}$} \\
\hline & Range & \begin{tabular}{|l|} 
Group 1 \\
Low
\end{tabular} & $\frac{\text { Group 2 }}{\text { Intermed. }}$ & $\frac{\text { Group 3 }}{\text { High }}$ & $\begin{array}{l}\text { Group 1 } \\
\text { Low }\end{array}$ & $\frac{\text { Group 2 }}{\text { Intermed. }}$ & $\begin{array}{l}\text { Group } 3 \\
\text { High }\end{array}$ \\
\hline $\begin{array}{l}\text { Perceived } \\
\text { Pressure }^{*}\end{array}$ & $1-7$ & $\begin{array}{l}4.87 \\
(1.23)\end{array}$ & $\begin{array}{l}4.54 \\
(1.28)\end{array}$ & $\begin{array}{l}4.51 \\
(1.33)\end{array}$ & $\begin{array}{l}5.30 \\
(1.07)\end{array}$ & $\begin{array}{l}4.51 \\
(1.32)\end{array}$ & $\begin{array}{l}3.81 \\
(1.42)\end{array}$ \\
\hline $\begin{array}{l}\text { Individual } \\
\text { Goal-Setting }\end{array}$ & $\begin{array}{l}-200- \\
+200\end{array}$ & $\begin{array}{l}-53.46 \\
(34.01)\end{array}$ & $\begin{array}{l}-3.30 \\
(25.83)\end{array}$ & \begin{tabular}{|l|}
46.07 \\
$(37.68)$
\end{tabular} & $\begin{array}{l}-36.04 \\
(40.22)\end{array}$ & \begin{tabular}{|l}
3.77 \\
$(31.20)$
\end{tabular} & \begin{tabular}{|l}
54.34 \\
$(43.60)$
\end{tabular} \\
\hline
\end{tabular}

Note: ${ }^{*}=$ composite score per construct, normalized with item count $(=3)$

First, we took a look at the means of our dependent variables and observed multiple things. (1) Concerning perceived pressure, we observed differing effects of the provision of RBPF in the different performance groups: For the subjects at the bottom of the ranking (low performers), perceived pressure increased 
$\left(\Delta_{\text {Low }}=.43\right)$. In contrast, for the subjects at the top of the ranking (high performers), the situation was perceived as less pressurizing $\left(\Delta_{\mathrm{High}}=-.70\right)$. Similarly, middle-ranked subjects (intermediate performers) also reported a lower level of perceived pressure. However, the measured decrease was quite small $\left(\Delta_{\text {Intermed. }}=\right.$ .03). (2) Concerning individual goal-setting, we saw an increase across all treatment groups. All subjects revised their goals upwards after being presented the RBPF. However, the increase for bottom ranked performers appeared to be the largest: While middle and top ranked individuals increased their self-set goals on average by 7.07 and 8.27 calls, respectively, subjects in the bottom performance group increased their goals by an average of 17.42 calls, which corresponds to an increase of five percentage points.

After this initial examination of our outcomes, we statistically tested for the significance of the observed differences within our three treatment groups. Both the assessment of QQ-Plots as well as the results of Shapiro-Wilk tests proved that the data for our two outcomes were non-normally distributed for both the NoRBPF and the RBPF situation. Thus, we turned to non-parametric two-sided paired Wilcoxon tests for our analysis. The results are displayed in Table $4(* * *$ $=\mathrm{p}<.001, * *=\mathrm{p}<.01, \mathrm{~ns}=$ non-significant) .

\section{Table 4. Intra-group analysis - results of Wilcoxon Signed-Rank Tests}

\begin{tabular}{|c|c|c|c|c|c|c|}
\hline Outcome & Group & Mdn NoRBPF & Mdn $n_{\text {RPF }}$ & Z & $\mathrm{p}$ & $\mathrm{r}^{6}$ \\
\hline \multirow{3}{*}{$\begin{array}{l}\text { Perceived } \\
\text { Pressure }\end{array}$} & Group 1 Low & 5.00 & 5.50 & -5.755 & $.000^{* * * *}$ & .724 \\
\hline & Group 2 Intermed. & 4.75 & 4.75 & -.326 & $.744^{\mathrm{ns}}$ & - \\
\hline & Group 3 High & 4.50 & 4.00 & -6.300 & $.000^{* * * *}$ & .899 \\
\hline \multirow{3}{*}{$\begin{array}{l}\text { Individual } \\
\text { Goal- } \\
\text { Setting }\end{array}$} & Group 1 Low & -50.00 & -30.00 & -4.812 & $.000^{* * *}$ & .594 \\
\hline & Group 2 Intermed. & 0.00 & 0.00 & -4.047 & $.000^{* * *}$ & .472 \\
\hline & Group 3 High & 50.00 & 60.00 & -2.963 & $.003^{* *}$ & .393 \\
\hline
\end{tabular}

We found that providing RBPF had significant influences with large effect sizes on the perceived pressure of bottom ranked individuals $\left(Z_{\text {PressureLow }}=-\right.$ 5.755 , p pressureLow $<.001$, rPressureLow $=.724)$ and top ranked individuals $\left(Z_{\text {PressureHigh }}=-6.300\right.$, p pressureHigh $<$ .001 , PressureHigh .899 ). More specifically, RBPF significantly increased pressure for low performers and significantly decreased it for high performers. In contrast, providing RBPF had no significant effect on the perceived pressure of intermediate performers $\left(Z_{\text {PressureIntermed. }}=-.326\right.$, p PressureIntermed. $\left.=.744\right)$. We thus rejected hypothesis $\mathrm{H} 1 \mathrm{~b}$, and accepted hypotheses $\mathrm{H1a}$ and H1c. These findings suggest that RBPF indeed

\footnotetext{
6 Effect sizes (r) of $.10 / .30 / .50$ are considered to be small/medium/large [53].
}

affects only the perceived pressure of subjects at the top or bottom of a ranking. More precisely, with regards to perceived pressure, the introduction of RBPF is only beneficial for individuals that rank high (they perceive less pressure). For low performers who rank at the bottom, the effect of using RBPF is actually negative since they perceive higher pressure.

Furthermore, we found that providing RBPF had significant influences with large and medium effect sizes, respectively, on the individual goal-setting of individuals in all three groups, i.e., bottom-ranked individuals $\quad\left(Z_{\text {Goal-SettingLow }}=-4.812, \quad\right.$ p Goal-SettingLow $<$ $\left..001, \mathrm{r}_{\text {Goal-SettingLow }}=.594\right)$, middle-ranked individuals $\left(Z_{\text {Goal-SettingIntermed. }}=-4.047, \quad p_{\text {Goal-SettingIntermed. }}<.001\right.$, $\mathrm{r}_{\text {Goal-SettingIntermed. }}=.472$ ), and top-ranked individuals $\left(\mathrm{Z}_{\text {Goal-SettingHigh }}=-2.963, \quad \mathrm{p}_{\text {Goal-SettingHigh }}<.01, \mathrm{r}_{\text {Goal- }}\right.$ SettingHigh $=.393)$. More specifically, RBPF significantly increased goal-setting for all individuals, that is, for all low, intermediate, and high performers. We thus accepted hypotheses $\mathrm{H} 2 \mathrm{a}, \mathrm{H} 2 \mathrm{~b}$, and $\mathrm{H} 2 \mathrm{c}$. These findings suggest that RBPF does increase the goalsetting of all subjects, independently of their position in the ranking. In other words, with regards to goalsetting, the introduction of RBPF may be beneficial to all users, regardless of their performance level and individual rank.

In conclusion, providing RBPF has different effects on subjects with different positions in the performance distribution. More specifically, RBPF is not unconditionally beneficial to all subjects within the performance distribution. Indeed, besides the positive effect on individual goalsetting, being compared to others simultaneously leads to higher perceived pressure for bottom-ranked individuals.

\section{Discussion}

Feedback can either be given by comparing subjects to a predefined external standard (criterionbased performance feedback, CBPF), or by relative performance feedback that enables interpersonal comparison, for example, in the form of rankings (RBPF). Recent evidence shows that people are interested in their (social) rank and that the human preference for high ranks in general increases subjects' performance, effort, and motivation $[4,5,7,8,51]$. However, rankings may create different feedback situations at the individual level. This is why recent research has turned to ranking effects and its consequences on individual behaviors and affections. Our paper contributes to the recent literature by examining RBPF's effects on perceived pressure and individual goal-setting, which are important drivers of workplace performance. First, we showed that an individual's performance level (high, intermediate, 
low) and their resulting ranking position (top, middle, bottom) strongly determines how they react to the provision of ranking feedback with regards to perceived pressure. Second, we showed that RBPF increases goal-setting for individuals of all ranking positions. Most notably, the effect on individual goalsetting is largest for bottom-ranked individuals.

More specifically, our results suggest that the effects of RBPF on perceived pressure strongly depend on an individual's position in the performance distribution. Introducing RBPF appears to reinforce the already existing variations of perceived pressure at different positions in the performance distribution. We already observed the highest scores of perceived pressure for the low performers who fell below a given reference level in CBPF. This insight is in line with other research results proving that receiving negative feedback (forced upward comparison) has negative effects on affections, e.g. leading to frustration and ego-deflation. By allowing low performers to compare themselves to others, pressure is greatly increased: Indeed, we found a steep increase in perceived pressure among low performers. Being compared to others makes them aware of their lack of skill, status, or position relative to their colleagues. In contrast, we found that high performers perceive the ranking situation as less pressuring. The downward comparisons reassure these individuals of their superiority, which subsequently reduces the stress of getting feedback and has soothing effects. Taken together, we conclude that providing ranking information has distinct effects on perceived pressure for individuals with differing performance levels, and that because of this, care should be taken when RBPF is introduced in the workplace.

In parallel to this, our results hint to the fact that the provision of RBPF can indeed be a useful tool to foster workplace performance. We found that after a ranking is introduced, low, intermediate, and high performers revise their self-set performance goals upwards. These overall positive ramifications across all three tested performance groups may be driven by several effects. First, introducing RBPF reduces performance ambiguity for all groups, which has been shown to be an important condition to developing realistic individual goals. In other words, receiving timely and accurate feedback that compares oneself to others reduces uncertainty about the true status of one's performance. In addition to this, providing ranking information also reduces the uncertainty of whether the externally provided goal is attainable. This is especially the case for low performers since the feedback reveals that others are proficient at the task, which can lead low performers to improve by observing high performers. Second, for high performers, the comparison with "worse-off" others serves the goal of self-enhancement, leveraging individuals' self-esteem and belief that they can further outperform others. The same holds true for middleranked subjects, since they get confirmation that they are capable of fulfilling requirements. Third, with regards to low performers, we found that the forced upward social comparison is seen as indicating a large potential for personal improvement. As such, RBPF appears to serve the goal of self-improvement.

\section{Limitations}

Our study has some limitations. First, the situation described in our vignette can never be fully realistic and is especially prone to individual misperceptions. In addition, our results might not hold true for nonEnglish speaking people, and differences might be found for other age groups. As a result, the external validity of our study might be limited. Although the scenario and the wording were carefully constructed, it is still possible that the respondents might have misinterpreted the situations. Indeed, the situation that was described in our fictitious scenario was not equally realistic for all respondents. For example, in the case of the students in our sample, it was maybe more difficult for them to place themselves in a working situation than it was for the employees in our sample.

Second, our intra-group results are prone to sequence effects. Due to the fact that subjects had to answer the same questionnaire twice, the results may be distorted since subjects may not have been blind to condition in the ranking situation. In other words, the answers in $\mathrm{t} 1$ could have been influenced by the baseline situation in $\mathrm{t} 0$. However, this limitation is mitigated by the inter-group analysis, which proved significant group differences in the reactions to the provision of RBPF.

Third, it is possible that our participants lacked the introspective ability to provide an accurate response to the self-reported measures, especially since they had to put themselves into a vignette situation. As a result, behavioral measures gathered in a field study would certainly be of value in order to confirm our results. Fourth, our research design is limited by presenting participants only with three possible ranking positions (top, middle, bottom), leaving out all other potential ranking positions as well as any potential effects driven by time-variant dynamics of a ranking.

\section{Conclusions}

Our findings hold important managerial implications with regards to the implementation of 
feedback systems in organizations. While the introduction of rankings seems to be beneficial for individual goal-setting, this positive effect comes with a price: Low-performers who find themselves at the bottom of the ranking perceive their situation as more pressuring compared to a situation without a ranking. These findings raise the question of the long-term effects of such feedback interventions. Research has already shown that higher pressure can lead to detrimental performance effects [26], unethical behavior [32], lower cooperation [31] and sabotage [30]. In particular, if existing performance and ability differences between employees are further stressed by rankings, situations are created in which lowperformers lag far behind and reaching the social standard seems impossible. In this case, rankings may have adverse effects on performance.

Hence, from a managerial perspective, it is important to mitigate the trade-off between leveraging self-set goals and increasing pressure for low performers. A possible solution might be to adjust the feedback regime to the performance level of employees. This may be especially beneficial for distributed teams that mainly interact via IS, since feedback interventions are then only minimally diluted by social interactions. First, it could be useful to form groups of employees of similar performance and ability in order to avoid a situation in which some individuals lag far behind others in the ranking. Second, adjusting feedback regimes to the performance groups could be another way of maximizing the positive effects of feedback provision. Indeed, RBPF regimes may be useful for enhancing the workplace performance of high performers due to their self-enhancement effects, but non-ranking feedback regimes such as comparison to the mean performance of others may be more suitable for low performers.

\section{References}

[1] Azmat, G., and N. Iriberri, "The Provision of Relative Performance Feedback: An Analysis of Performance and Satisfaction", Journal of Economics \& Management Strategy 25(1), 2016, pp. 77-110.

[2] Bandura, A., and D. Cervone, "Self-Evaluative and SelfEfficacy Mechanisms Governing the Motivational Effects of Goal Systems.", Journal of Personality and Social Psychology 45(5), 1983, pp. 1017-1028.

[3] Blanes i Vidal, J., and M. Nossol, "Tournaments without Prizes: Evidence from Personnel Records", Management Science 57(10), 2011, pp. 1721-1736.

[4] Villeval, M.C., Performance Feedback and Peer Effects, 2020.

[5] Gill, D., Z. Kissova, J. Lee, and V.L. Prowse, "First-Place Loving and Last-Place Loathing: How Rank in the Distribution of Performance Affects Effort Provision",
Management Science 65(2), 2018, pp. 494-507.

[6] Kirchler, M., U. Weitzel, and F. Lindner, "Rankings and Risk-Taking in the Finance Industry", Journal of Finance 73(5), 2018, pp. 2271-2302.

[7] Hannan, R.L., G.P. McPhee, A.H. Newman, and I.D. Tafkov, "The Effect of Relative Performance Information on Performance and Effort Allocation in a Multi-Task Environment", The Accounting Review 88(2), 2013, pp. 553-575.

[8] Jalava, N., J.S. Joensen, and E. Pellas, "Grades and Rank: Impacts of Non-Financial Incentives on Test Performance", Journal of Economic Behavior and Organization 115(2015), 2015, pp. 161-196.

[9] Tran, A., and R. Zeckhauser, "Rank as an Inherent Incentive: Evidence from a Field Experiment", Journal of Public Economics 96(10), 2012, pp. 645-650.

[10] Blanton, H., B.P. Buunk, F.X. Gibbons, and H. Kuyper, "When Better-Than-Others Compare Upward: Choice of Comparison and Comparative Evaluation as Independent Predictors of Academic Performance.", Journal of Personality and Social Psychology 76(3), 1999, pp. 420-430.

[11] Corgnet, B., J. Gómez-Miñambres, and R. HernánGonzález, "Goal Setting and Monetary Incentives: When Large Stakes Are Not Enough", Management Science 61(12), 2015, pp. 2926-2944.

[12] Kluger, A.N., and A. DeNisi, "The Effects of Feedback Interventions on Performance: A Historical Review, a Meta-Analysis, and a Preliminary Feedback Intervention Theory.”, Psychological Bulletin 119(2), 1996, pp. 254284

[13] Latham, G.P., and E.A. Locke, "A Theory of Goal Setting and Task Performance", Organizational Behavior and Human Decision Processes 50(1991), 1991, pp. 212-247.

[14] Locke, E.A., K.N. Shaw, L.M. Saari, and G.P. Latham, "Goal Setting and Task Performance: 1969-1980.", Psychological Bulletin 90(1), 1981, pp. 125-152.

[15] Seta, J.J., C.E. Seta, and S. Donaldson, "The Impact of Comparison Processes on Coactor's Frustration and Willingness to Expend Effort", Personality and Social Psychology Bulletin 17(5), 1982, pp. 560-568.

[16] Garcia, S.M., A. Tor, and R. Gonzalez, "Ranks and Rivals: A Theory of Competition”, Personality \& Social Psychology Bulletin 32(7), 2006, pp. 970-982.

[17] Huschens, M., F. Rothlauf, and R. Rothe, "On the Role of Social Comparison Processes in Gamified Work Situations", Proceedings of the 52nd Hawaii International Conference on System Sciences, 2019, pp. 1446-1455.

[18] Wills, T.A., "Downward Comparison Principles in Social Psychology", Psychological Bulletin 90(2), 1981, pp. 245-271.

[19] Wood, J. V., and K.L. Taylor, "Serving Self-Relevant Goals through Social Comparison", In J. Suls and T.A. Wills, eds., Social Comparison: Contemporary Theory and Research. Lawrence Erlbaum Associates, Hillsdale, NJ, 1991, 23-49.

[20] Ramaprasad, A., "On the Definition of Feedback", Behavioral Science 28(1), 1983, pp. 4-13.

[21] Eriksson, T., A. Poulsen, and M.C. Villeval, "Feedback 
and Incentives: Experimental Evidence", Labour Economics 16(6), 2009, pp. 679-688.

[22] Cherry, T.L., and L. V. Ellis, "Does Rank-Order Grading Improve Student Performance?: Evidence from a Classroom Experiment", International Review of Economics Education 4(1), 2005, pp. 9-19.

[23] Lok, B., C. McNaught, and K. Young, "CriterionReferenced and Norm-Referenced Assessments: Compatibility and Complementarity", Assessment \& Evaluation in Higher Education 41(3), 2016, pp. 450465.

[24] Jung, J.H., C. Schneider, and J. Valacich, "Enhancing the Motivational Affordance of Information Systems: The Effects of Real-Time Performance Feedback and Goal Setting in Group Collaboration Environments", Management Science 56(4), 2010, pp. 724-742.

[25] Delfgaauw, J., R. Dur, J. Sol, and W. Verbeke, "Tournament Incentives in the Field: Gender Differences in the Workplace", Journal of Labor Economics 31(2), 2013, pp. 305-326.

[26] Baumeister, R.F., and C.J. Showers, "A Review of Paradoxical Performance Effects: Choking Under Pressure in Sports and Mental Tests", European Journal of Social Psychology 16(4), 1986, pp. 361-383.

[27] Festinger, L., "A Theory of Social Comparison Processes”, Human Relations 7(2), 1954, pp. 117-140.

[28] Kilduff, G.J., "Driven to Win: Rivalry, Motivation, and Performance", Social Psychological and Personality Science 5(8), 2014, pp. 944-952.

[29] Garcia, S.M., A. Tor, and T.M. Schiff, "The Psychology of Competition: A Social Comparison Perspective", Perspectives on Psychological Science 8(6), 2013, pp. 634-650.

[30] Hartmann, F., and P. Schreck, "Rankings, Performance, and Sabotage: The Moderating Effects of Target Setting”, European Accounting Review 27(2), 2016, pp. 363-382.

[31] Poortvliet, P.M., O. Janssen, N.W. Van Yperen, and E. Van de Vliert, "Low Ranks Make the Difference: How Achievement Goals and Ranking Information Affect Cooperation Intentions", Journal of Experimental Social Psychology 45(5), 2009, pp. 1144-1147.

[32] Vriend, T., J. Jordan, and O. Janssen, "Reaching the Top and Avoiding the Bottom: How Ranking Motivates Unethical Intentions and Behavior", Organizational Behavior and Human Decision Processes 137(2016), 2016, pp. 142-155.

[33] Pedro, L.Z., A.M.Z. Lopes, B.G. Prates, J. Vassileva, and S. Isotani, "Does Gamification Work for Boys and Girls?", Proceedings of the 30th Annual ACM Symposium on Applied Computing - SAC '15, ACM (2015), 214-219.

[34] Buunk, B.P., R.L. Collins, S.E. Taylor, N.W. VanYperen, and G.A. Dakof, "The Affective Consequences of Social Comparison: Either Direction Has Its Ups and Downs", Journal of Personality and Social Psychology 59(6), 1990, pp. 1238-1249.

[35] Collins, R.L., "For Better or Worse: The Impact of Upward Social Comparison on Self-Evaluations.", Psychological Bulletin 119(1), 1996, pp. 51-69.

[36] Santhanam, R., D. Liu, and W.C.M. Shen,
"Gamification of Technology-Mediated Training: Not All Competitions are the Same", Information Systems Research 27(2), 2016, pp. 453-465.

[37] Tolli, A.P., and A.M. Schmidt, "The Role of Feedback, Causal Attributions, and Self-Efficacy in Goal Revision.", Journal of Applied Psychology 93(3), 2008, pp. 692-701.

[38] Bandura, A., and D. Cervone, "Differential Engagement of Self-Reactive Influences in Cognitive Motivation", Organizational Behavior and Human Decision Processes 38(1), 1986, pp. 92-113.

[39] Locke, E.A., E. Frederick, C. Lee, and P. Bobko, "Effect of Self-Efficacy, Goals, and Task Strategies on Task Performance", Journal of Applied Psychology 69(2), 1984, pp. 241-251.

[40] Landers, R.N., K.N. Bauer, and R.C. Callan, "Gamification of Task Performance with Leaderboards: A Goal Setting Experiment", Computers in Human Behavior 71, 2017, pp. 508-515.

[41] Taylor, S.E., and M. Lobel, "Social Comparison Activity Under Threat: Downward Evaluation and Upward Contacts", Psychological Review 96(4), 1989, pp. 569-575.

[42] Bandura, A., "Self-Efficacy: Toward a Unifying Theory of Behavioral Change.", Psychological Review 84(2), 1977, pp. 191-215.

[43] Rossi, P.H., and A.B. Anderson, "The Factorial Survey Approach: An Introduction", Measuring Social Judgments: The Factorial Survey Approach, 1982, pp. $15-67$.

[44] Atzmüller, C., and P. Steiner, "Experimental Vignette Studies in Survey Research", Methodology 6(3), 2010, pp. 128-138.

[45] Ryan, R.M., and E.L. Deci, "Intrinsic and Extrinsic Motivations: Classic Definitions and New Directions", Contemporary Educational Psychology 25, 2000, pp. 54-67.

[46] Elliot, A.J., and M. V. Covington, "Approach and Avoidance Motivation", Educational Psychology Review 13(2), 2001, pp. 73-92.

[47] Gibbons, F.X., and B.P. Buunk, "Individual Differences in Social Comparison: Development of a Scale of Social Comparison Orientation.”, Journal of Personality and Social Psychology 76(1), 1999, pp. 129-142.

[48] Ringle, C.M., S. Wende, and J.-M. Becker, SmartPLS 3, 2015.

[49] Hair, J.F., C.M. Ringle, and M. Sarstedt, "PLS-SEM: Indeed a Silver Bullet", Journal of Marketing Theory and Practice 19(2), 2011, pp. 139-152.

[50] Hair, J.F., W.C. Black, B.J. Babin, and R.E. Anderson, Multivariate Data Analysis, Prentice Hall, Upper Saddle River, NJ, 2009.

[51] Azmat, G., M. Bagues, A. Cabrales, and N. Iriberri, "What You Know Can't Hurt You (For Long): A Field Experiment on Relative Performance Feedback in Higher Education", 2015, pp. 1-43.

[52] Lazear, E.P., and S. Rosen, "Rank-Order Tournaments as Optimum Labor Contracts", Journal of Political Economy 89(5), 1981, pp. 841-864.

[53] Rosenthal, R.J., "Meta-Analytic Procedures for Social Research", SAGE (1991). 